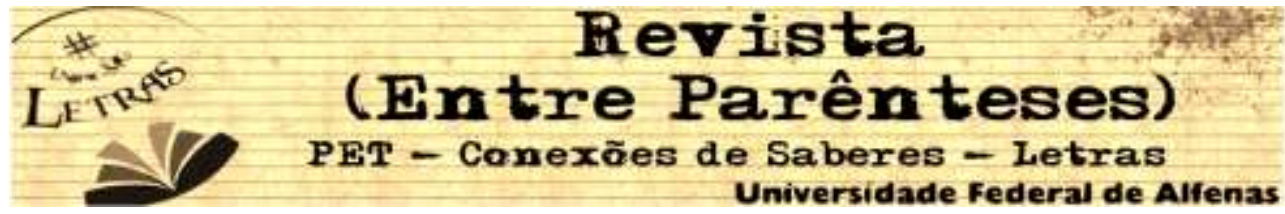

\title{
Vidas Secas: interface entre literatura e cinema
}

\author{
Arlete Ferreira dos Santos ${ }^{1}$ \\ Simone da Silva Santos Moura ${ }^{1}$ \\ Viviana de Souza ${ }^{1}$ \\ Ângela Vilma Santos Bispo Oliveira ${ }^{2}$
}

RESUMO: Desde o surgimento do cinema, percebeu-se que a nova arte tinha a capacidade de relatar, com seus próprios recursos, uma narrativa que antes era contada em romances ou contos. Desse modo, surgiu-se a prática de adaptar uma narrativa literária em uma narrativa fílmica, a ponto de grande parte dos filmes ter atualmente, como origem, não um script original, criado especialmente para o cinema, mas uma obra literária. Nessa perspectiva, o presente trabalho se fundamenta em um estudo comparativo entre a obra "Vidas Secas" de Graciliano Ramos e a produção cinematográfica da mesma obra, dirigida por Nelson Pereira dos Santos (1963). O objetivo de análise desse estudo é observar se há "fidelidade" por parte do filme com relação à obra e a estrutura técnica e simbólica do filme, assim como, analisar a forma pela qual o diretor busca por meio dos recursos cinematográficos ilustrar as palavras de Graciliano Ramos através da linguagem fílmica. Faz-se necessário entender que numa produção fílmica, a compreensão se dá de forma diferenciada do texto escrito, pois, mesmo usando a nossa imaginação, o intelecto não atua tanto, uma vez que a sequência de imagens contribui para influenciar os nossos sentimentos de forma direta. Nesse sentido, cabe dizer conforme Mendes (2009), que "um filme não é pensado, é percebido, é sentido". Nele são utilizadas várias linguagens, que afetam o espectador de maneira mais direta e precisa com relação ao mecanismo da literatura.

Palavras-chave: Cinema. Câmera. Vidas Secas. Linguagem Cinematográfica.

ABSTRACT: Since the beginning of cinema, it was noticed that this new art had the ability to report, with its own resources, a narrative that was previously told in novels or short stories. In this way, occurs the practice of adapting a literary narrative in a cinematic narrative. Consequently, most films currently have, in source, not an original script, created especially for the cinema, but a literary work. In this perspective, this work is based on a comparative study of the literature "Vidas Secas" from Graciliano Ramos and a film production of the same literature, directed by Nelson Pereira dos Santos (1963). The goal of this analysis is to attend if exist "loyalty" from the side of the film with respect the literature work and the technical and symbolic structure of the movie, as well as analyze the way of the director search by cinematographic resources to illustrate the words of Graciliano Ramos through filmic language. It is necessary to understand that in a film production, the comprehension takes a different way of the written text, because, even using our imagination, the intellect does not act quite, since the sequence of images helps to shape our feelings so directly. It this sense, it is worth mentioning as Mendes (2009), that "a movie is not thought, is perceived, is felt". In it, several languages are used, affecting the spectator more directly and accurately with respect to the literature mechanism.

Keywords: Cinema. Camera. Vidas Secas. Cinematic language.

\footnotetext{
${ }^{1}$ Graduandas do curso de Letras, Libras, Língua Estrangeira. Centro de Formação de ProfessoresCFP da Universidade Federal do Recôncavo da Bahia- UFRB

${ }^{2}$ Prof $^{-}$Dr $^{a}$. atuante no Centro de Formação de Professores- CFP da Universidade Federal do Recôncavo da Bahia- UFRB.
} Revista (Entre Parênteses) ISSN 2238-4502 


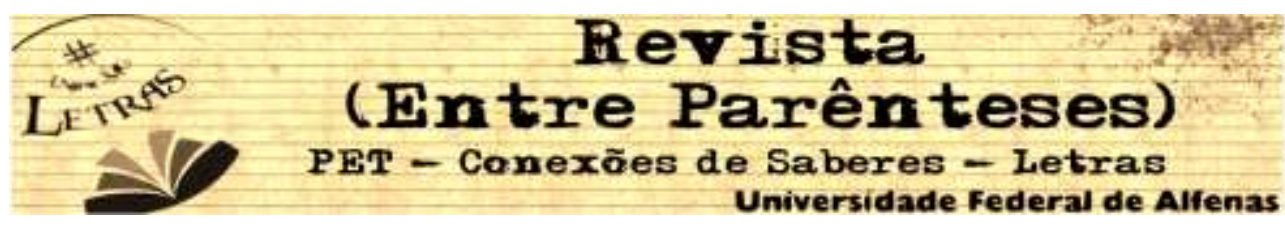

\section{Introdução}

Desde o surgimento do cinema, percebeu-se que a nova arte tinha a capacidade de relatar, com seus próprios recursos, uma narrativa que antes era contada em romances ou contos. Desse modo, surgiu a prática de adaptar uma narrativa literária em uma narrativa fílmica, a ponto de grande parte dos filmes ter atualmente, como origem, não um script original, criado especialmente para o cinema, mas uma obra literária. O processo de adaptação vem sendo considerado como unidirecional, ou seja, caminhando consecutivamente do literário para o fílmico e priorizando sempre o primeiro em detrimento do segundo.

Partindo desse ponto, o presente trabalho se fundamenta em um estudo comparativo entre a obra "Vidas Secas", de Graciliano Ramos, e a produção cinematográfica da mesma obra, dirigida por Nelson Pereira dos Santos (1963). objetivo de análise deste estudo é observar se há "fidelidade" por parte do filme com relação à obra e a estrutura técnica e simbólica do filme, assim como analisar a forma pela qual o diretor busca por meio dos recursos cinematográficos ilustrar as palavras de Graciliano Ramos através da linguagem fílmica.

O cinema era visto pelas pessoas consideradas cultas como um ambiente de desprestígio, desvalorizado e as pessoas que frequentavam esse espaço sofriam certo preconceito, sendo classificadas como indivíduos desocupados. Diante disso, o cinema veio ganhando espaço em meados dos anos 20, deixando de ser uma mera reprodução da realidade em movimento, passando a ser considerado uma linguagem artística, fundamentada na reprodução da realidade.

Em época recente, o cinema ganha o reconhecimento de um lugar que possui a capacidade, não apenas de reproduzir a realidade, mas de reconstruí-la, tornandoa completamente original. Nesse sentido, o cinema se difere de outras artes, como a literatura e a pintura, na medida em que possui autonomia de transformar o mundo em discurso, utilizando-se do próprio mundo; enquanto que a literatura e a pintura, por exemplo, utilizam de sinais arbitrários como substituição do mundo.

O fato de o cinema ter a competência de transformação nos remete a afirmar que ele possui uma atitude escritural que é somada ao seu caráter fotorreprodutor 


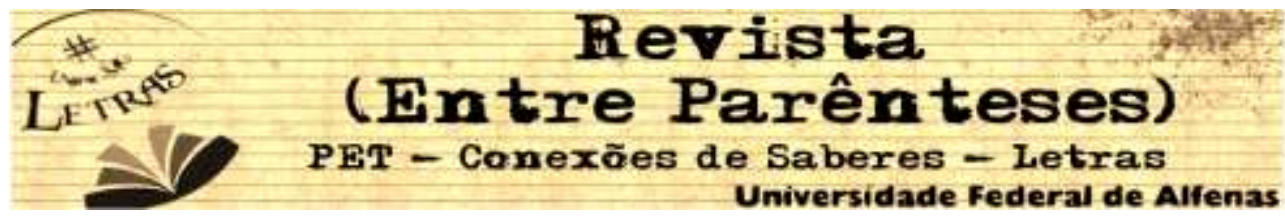

originário. E, devido a esse motivo, surge o filme, ou seja, um discurso dentro do sistema de uma linguagem representada pelo cinema que utiliza da representação sonora para reproduzir um drama. Para Setaro (2010), o filme tem a capacidade de recriar a realidade por meio de uma linguagem, transformando-o num gênero técnico-formal mais voltado para a expressão do que para a comunicação.

No entanto, apesar de a literatura e o cinema apresentarem uma interrelação, a experiência do leitor e do espectador se dá de forma diferenciada, uma vez que o leitor tem a possibilidade, por meio da obra literária, de retomar trechos já lidos ou até mesmo ter acesso ao final da obra de forma antecipada. Enquanto que no cinema, o espectador fica impossibilitado de retomar cenas mais comoventes ou adiantá-las, a fim de descobrir o final da produção fílmica. A esse respeito, Nazário menciona:

\begin{abstract}
Podemos fechar um livro a qualquer momento, ler certas passagens com maior ou menor velocidade, voltar alguns capítulos e reler uma descrição que só então ganha sentido, avançar até a última página e descobrir como tudo termina. Na sala de projeções, estamos imobilizados e mobilizados, (...) indefesos: só podemos esperar que as imagens imponham-se sobre nós com sua extensão, ritmo, configuração e continuidade, estabelecidas de uma vez por todas por quem as assim estendeu, ritmou, configurou e deu continuidade. Fora do alcance de nossas mãos, as imagens nos diminuem e dominam (NAZÁRIO 1999, p.90 apud PEREIRA 2010, p.1)
\end{abstract}

Desse modo, o cinema exige maior atenção do espectador para que nenhuma cena passe despercebida, considerando que, quando isso ocorre, a compreensão do filme fica comprometida.

O cinema, assim como obras de outros gêneros, possui uma linguagem que, embora não seja perceptível pelos espectadores, se estabelece na narrativa que consiste na manipulação dos elementos da linguagem fílmica pelo realizador cinematográfico. Dessa forma, o filme possui uma linguagem específica como ressalta Setaro:

(...) o que merece crédito na obra cinematográfica não é o que se diz "no" filme, mas, sim, o que o filme "diz". E este "fala" por meio de sua linguagem específica, assim como na literatura o escritor se expressa por um conjunto de palavras que formam frases, orações e períodos. A expressão daquele que escreve se dá através da sintaxe. E o cinema também tem uma sintaxe 


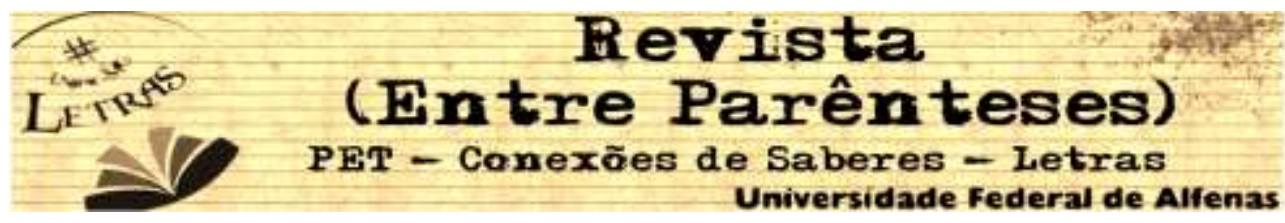

que se cristaliza pelo relacionamento dos planos, das cenas, das sequências (SETARO, 2010, p. 31).

Assim sendo, a sintaxe cinematográfica é estabelecida pela câmera, uma vez que a mesma possibilita a realização de elementos determinantes para a execução da linguagem, como: a planificação, os movimentos da câmera e a angulação.

A compreensão de um texto escrito acontece quando o leitor, além de lê-lo, o assimila através de uma ação consciente e de uma predisposição aliada ao intelecto. Isso atinge sua imaginação e suas emoções. Numa produção fílmica, a compreensão se dá de forma diferenciada, pois, mesmo usando a nossa imaginação, o intelecto não atua tanto, uma vez que a sequência de imagens contribui para influenciar os nossos sentimentos de forma direta. Nesse sentido, cabe dizer, conforme Mendes (2009), que "Um filme não é pensado, é percebido, é sentido". Nele são utilizadas várias linguagens, que afetam o espectador de maneira mais direta e precisa com relação ao mecanismo da literatura. Assim, a adaptação de uma obra literária para o cinema não se limita apenas à imitação através das imagens, mas deve revelar o que está nas entrelinhas da obra.

Observando o início da obra "Vidas Secas" e, fazendo uma comparação com o início do filme, percebemos que a câmera ocupa o lugar de narrador de forma silenciada, pois o que mostra na cena são os espaços do sertão nordestino marcado pela seca e pela presença dos personagens que caminham na esperança de uma vida melhor.

Nesse sentido, o romance mostra que nem sempre é possível superar as dificuldades impostas pela seca e, por vezes é necessário migrar de "sua" terra em busca de melhores condições de vida. O início da obra apresenta Fabiano e sua família que vão à procura de sobrevivência, da mesma forma, o final da obra apresenta esse êxodo. A fuga do nordestino é comum e se sobressai em Vidas Secas, como observamos no seguinte trecho:

(...) entristeceu. Considerar-se plantado em terra alheia! Engano. A sina dele era correr mundo, andar para cima e para baixo, à toa, como judeu errante. Um vagabundo empurrado pela seca. Achava-se ali de passagem, era hóspede. Sim, senhor, hóspede que se demorava demais, tomava 


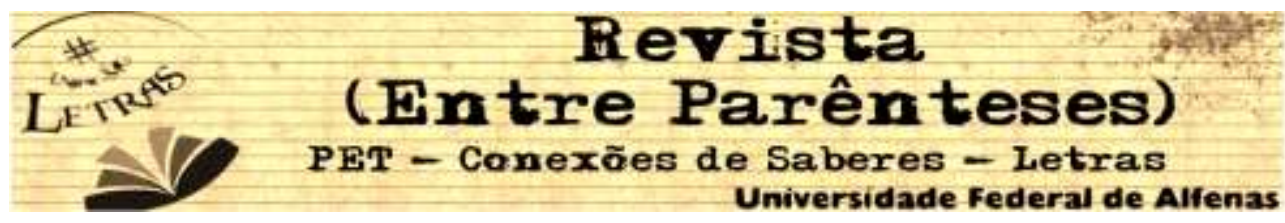

amizade à casa, ao curral, ao chiqueiro das cabras, ao juazeiro que os tinha abrigado uma noite (RAMOS, 2009, p. 19).

O filme revela fidelidade à obra literária, uma vez que o início e o final do filme apresentam Fabiano e sua família, que são obrigados a abandonar o seu lugar, indo em busca de sobrevivência em outros lugares.

Contudo, observa-se que o filme não segue a linearidade dos fatos conforme a obra, visto que na obra são apresentados os capítulos da seguinte forma: Mudança; Fabiano; Cadeia; Sinhá Vitória; O menino mais novo; O menino mais velho; Inverno; Festa; Baleia; Contas; O soldado amarelo; O mundo coberto de penas e Fuga. Já o filme constitui-se numa ordenação diferente, pois os capítulos apresentam-se diluídos, seguindo uma ordenação lógica. Desse modo, enquanto que na obra literária os fatos são estanques, na produção fílmica, os fatos estão condensados, como por exemplo, os capítulos "Cadeia" e "Festa" que na obra são postos separadamente, no filme, encontram-se mesclados, considerando que no momento em que ocorre a festa, paralelamente, ocorre a prisão de Fabiano.

Do mesmo modo, no filme há o deslocamento de capítulos, como "O soldado amarelo", que narra o reencontro de Fabiano com o soldado responsável pela sua prisão, o qual antecede o capítulo que narra a morte de Baleia, ao contrário do texto literário.

Outro aspecto que difere o filme da obra literária é a presença de um personagem que faz companhia a Fabiano na cela, este que por sua vez é afilhado de um capitão do cangaço, que ao chegar à cidade, liberta Fabiano juntamente com o seu companheiro de cela. No romance, enquanto estava na prisão, Fabiano sonhava em tornar-se um cangaceiro para se vingar do soldado amarelo como descrito trecho seguinte:

Carregaria a espingarda e daria um tiro de pé de pau no soldado amarelo. Não. O soldado amarelo era um infeliz que nem merecia um tabefe com as costas da mão. Mataria os donos dele. Entraria num bando de cangaceiros e faria estrago nos homens que dirigiam o soldado amarelo. Não ficaria um para a semente. Era a ideia que the fervia na cabeça. Mas havia a mulher, havia os meninos, havia a cachorrinha (RAMOS, 1966, p. 42). 


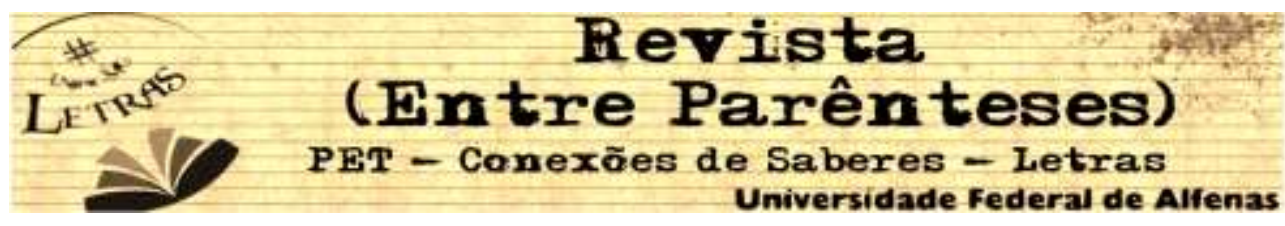

O fato de ter introduzido um novo personagem no filme fez com que o diretor proporcionasse a Fabiano outra oportunidade de vida, considerando que o mesmo oferece a Fabiano a possibilidade de realizar aquilo que na obra literária era apenas um sonho: tornar-se cangaceiro. Nesse sentido, se Fabiano aceitasse a proposta ofertada por Nelson Pereira dos Santos, estaria alterando de forma radical a narrativa escrita por Graciliano Ramos. Esse episódio revela a impossibilidade de mudança para Fabiano, que agora é prisioneiro do seu próprio destino, não havendo para ele alternativa que não seja a permanência ao lado da família.

Diante disso, percebe-se que o cinema e a literatura possuem semelhanças marcantes, visto que ambas são capazes, como nos diz Mendes (2009), "de criar personagens e ações, situá-los no tempo e lugar, e finalmente transportar o espectador aos mundos da ficção".

A infelicidade desses personagens descrita na obra literária é recriada no filme de Nelson Pereira dos Santos, tanto pelas fisionomias dos personagens, quanto pela ausência de uma trilha sonora, não expressando uma musicalidade.

O som que aparece no filme corresponde ao ruído de um carro de bois, que se adéqua ao próprio ambiente pela ausência de vivacidade. Esse silêncio é percebido também, por meio da interação entre os personagens, que se dá de forma fragmentada, os diálogos são escassos, as palavras não se firmam, como podemos observar em um trecho da obra, em que há uma conversa entre sinhá Vitória e Fabiano:

\footnotetext{
Não era propriamente conversa: eram frases soltas, espaçadas, com repetições e incongruências. Às vezes uma interjeição gutural dava energia ao discurso ambíguo. Na verdade nenhum deles prestava atenção às palavras do outro: iam exibindo as imagens que lhes vinham ao espírito, e as imagens sucediam-se, deformavam-se, não havia meio de dominá-las. Como os recursos de expressão eram minguados, tentavam remediar a deficiência falando alto (RAMOS, 1966, p. 80).
}

Nesse sentido, observa-se que esse trecho descrito no romance é apresentado no filme por Nelson Pereira com certa "fidelidade", pois, no instante em que Fabiano e sinhá Vitória estão "dialogando", a câmera cumpre o papel de mostrá- 


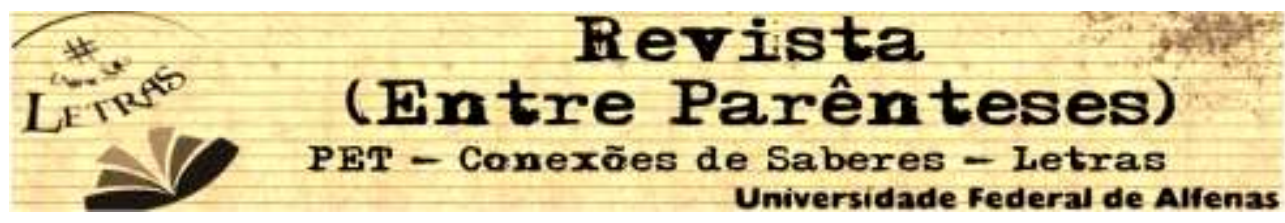

los em primeiro plano. Nesse instante em que a câmera foca a imagem de um deles conversando, ouve-se o som diegético deslocado da fala do outro personagem.

Diante desse contexto, percebemos que não há uma preocupação entre os personagens de ouvir o que o outro está falando, pois eles falam simultaneamente, o que demonstra uma forma de desabafo de suas angústias e explanação de seus sonhos. Assim, essa cena caracteriza uma forma de transposição de linguagens muito bem elaborada, em que o diretor consegue expressar através de imagens o que Graciliano Ramos escreveu na obra.

Outro trecho da obra que merece ser destacado no romance remete à morte da cachorra Baleia. Segundo Mendes (2009) "Nelson Pereira dos Santos soube captar toda a beleza expressa por Graciliano Ramos ao descrever a agonia da cachorra frente à morte e nos premiou com imagens que transbordam poesia". No discorrer do romance somos confrontados com a humanização da cachorra Baleia, que apesar de ser um animal irracional é descrita com características próprias do ser humano. Essas características são apresentadas no momento agonizante de sua morte, em que ela tem alucinações com preás.

No filme, o diretor apresenta com fidelidade esse recorte da obra ao mostrar 0 sentimento de Baleia caracterizado pelo afastamento da realidade e pela tentativa de reviver o passado. Não importando assim, conforme Mendes (2009), o que vitimou Baleia, tampouco a seca, nem o sofrimento do homem em meio a sua miséria, mas o que nos arrebata e sensibiliza nesta cena é o ato humano de morrer.

Além de Baleia, outro personagem que merece destaque é Fabiano, que carrega em si as características próprias do sertão nordestino. As ausências do verde na natureza, dos rios que correm em direção ao mar refletem sobre esse personagem, revelando a secura de sua existência, a dignidade que não lhe fora oferecida. Vejamos o seguinte trecho da obra:

E, pensando bem ele não era homem: era apenas um cabra ocupado em guardar coisas dos outros. Vermelho, queimado, tinha os olhos azuis, a barba e os cabelos ruivos; mas como vivia em terra alheia, cuidava dos animais alheios, descobria-se, encolhia-se na presença dos brancos e julgava-se cabra. (...) Você é um bicho, Fabiano (RAMOS, 2011.p. 18-19). 


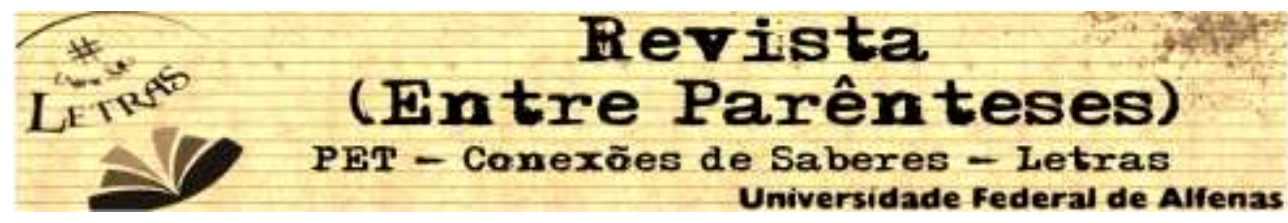

A forma como Fabiano é descrito na obra, demonstra a sua semelhança com o lugar onde vive: "vermelho, queimado, não é um homem é um cabra", que, adaptado àquele lugar extinguiu o seu próprio humano, colocando-se numa postura de submissão, "encolhendo-se na presença dos brancos". A vida não the reservou sequer a valentia dos "cabras", secaram-se nele a arrogância, a petulância, típicas dos homens que se denominam "cabras".

No seu reencontro com o soldado amarelo, responsável pela sua prisão, ele tem a chance de vingar 0 ato de ter sido preso injustamente, no entanto, não concretiza a vingança por falta de coragem. Observemos:

\footnotetext{
O soldado, magrinho, enfezadinho, tremia. E Fabiano tinha vontade de levantar o facão de novo. Tinha vontade, mas os músculos afrouxavam. (...) e ele estava indeciso, de olho arregalado, respirando com dificuldade, um espanto verdadeiro no rosto barbudo coberto de suor, o cabo do facão mal seguro entre os dois dedos úmidos. (...) O soldado encolhia-se, escondia-se por detrás da árvore (RAMOS, 2011, p. 102-104).
}

Esse fragmento é exposto de forma clara e com precisão no filme, através do jogo de imagens proporcionada pela câmera, que ora focaliza o soldado amarelo, ora focaliza Fabiano. Assim, a câmera exerce um papel fundamental no desenrolar da narrativa, pois ela controla ou determina as percepções da plateia, mostrando seu ponto de vista, trazendo uma aproximação ou um distanciamento da imagem; ocultando ou esclarecendo seu foco e destacando seu ângulo de visão. Assumindo, desse modo, além da função de narrador, o papel de uma autêntica contadora de estórias, ao se referir a "mundos imaginários".

Vale destacar também, além desses personagens já mencionados, o filho de Fabiano "o menino mais velho", na obra Vidas Secas. Esse nunca ouvira falar na palavra "inferno", que foi pronunciada pela sinhá Terta. Após ouvir a expressão, o garoto indaga a mãe sobre o seu significado. A mãe, no entanto, alude vagamente a certo lugar ruim. O garoto não se contenta com a resposta e vai tentar obtê-la através do pai, que por sua vez, não Ihe dá nenhuma resposta. Sem conseguir resposta alguma, o menino retorna e indaga novamente à mãe, que fala de espetos quentes e fogueiras. Logo após ouvir, o garoto pergunta se ela já tinha ido lá, motivo 


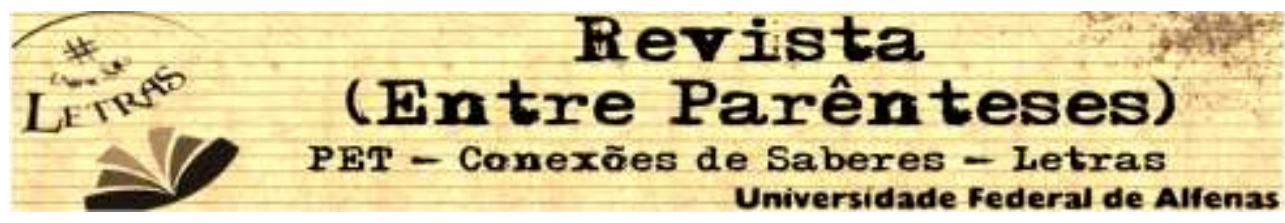

esse porque acaba apanhando. No filme, a cena ganha uma expressividade muito grande. Ao sentar-se lá fora, embaixo de uma árvore, o garoto repete várias vezes a palavra "inferno", nesse momento, à medida que o garoto repetia a palavra, a câmera deslizava por todos os lugares ao redor: a casa, o sol quente, a caatinga, o céu cheio de aves, se detendo momentaneamente nesses espaços, expandindo a relação significante/ significado. Nesse instante, era como se o menino dissesse, ou até mesmo se desse conta de que o inferno era aquele lugar em que viviam.

Nesse sentido, a discussão realizada até aqui nos faz perceber que a linguagem cinematográfica é a forma mais extraordinária que o ser humano elaborou para reproduzir sua visão sobre a natureza e recriar o mundo por meio de sua própria imagem. E, no momento em que o diretor consegue transpor o texto literário para a linguagem cinematográfica, essa ação ocorre por meio de uma tradução visual, que requer um exercício de criatividade imagética.

Portanto, ao relacionar o filme e a obra literária "Vidas Secas", percebe-se que a linguagem presente nesses dois gêneros possui suas próprias especificidades. Vale ressaltar que o filme mantém certa fidelidade à obra, sendo apresentado por cenas que reconstroem trechos do texto literário com precisão, pois Nelson Pereira dos Santos conseguiu transpor a obra de Graciliano Ramos para a linguagem cinematográfica sem que houvesse a perda de autenticidade do autor, tornando-se assim, outra obra, concluída e singular.

\section{Referências}

MENDES, Lena. Vidas Secas: cinema e literatura. Universidade Federal Fluminense (UFF), 2009. Disponível em:

<http://www.revistaicarahy.uff.br/revista/html/numeros/1/dliteratura/LENA MENDES. pdf>. Acesso em: 22 set. 2013.

PEREIRA, Maria do Rosário Alves. Literatura e cinema: Vidas Secas. Darandina, Revisteletrônica- Programa de Pós-Graduação em Letras/UFJF- volume 1- número 2, 2010. Disponível em: <http://www.ufjf.br/darandina/files/2010/01/artigo041.pdf>. Acesso em: 22 set. 2013. 


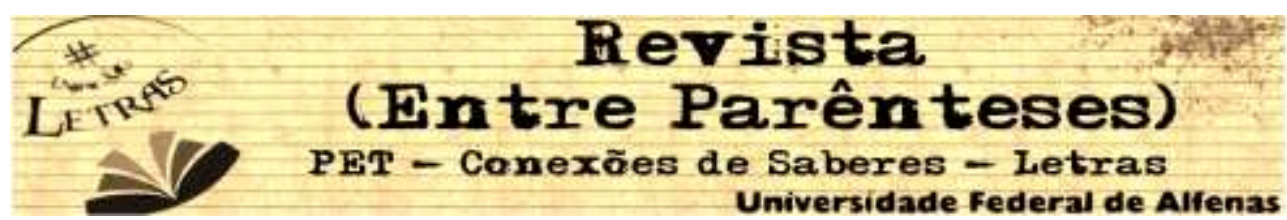

RAMOS, Graciliano. Vidas Secas. Rio de Janeiro: Record, 2011.

SANTOS, Nelson Pereira dos. Vidas Secas de Graciliano Ramos. 1963.

SETARO, André. RIBEIRO, Carlos (Orgs.). Como o cinema "fala". In. Escritos sobre cinema: trilogia de um tempo crítico. Salvador: EDUFBA: Azougue Editorial, 2010. A escalada do cinema enquanto linguagem. In. Escritos sobre cinema: trilogia de um tempo crítico. Salvador: EDUFBA: Azougue Editorial, 2010.

Recebido em: 11 jun. 2014. Aceito em: 22 set. 2014. 